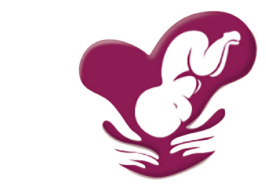

Published By : PERINASIA The Indonesian Society of Perinatology

\section{Doula Support in The Success of a Normal Delivery}

'Obstetric and Gynecologic Department Medical Faculty Udayana University Sanglah General Hospital, Denpasar, Bali,Indonesia.

${ }^{2}$ Outpatient Clinic Sanglah General Hospital Denpasar, Bali, Indonesia. ${ }^{3}$ Kasih Medika Pregnancy School, Denpasar, Bali, Indonesia.

\section{*Corresponding to:}

I Nyoman Hariyasa Sanjaya, Obstetric and Gynecologic Department

Medical Faculty Udayana University

Sanglah General Hospital, Denpasar,

Bali,Indonesia.

hariyasa_sanjaya@unud.ac.id

Received: 2021-07-20

Accepted: 2021-08-29

Published: 2021-09-11

\section{ABSTRACT}

Introduction: Many mothers who give birth are less interested in giving birth normally because of the intense labor pain. Actually it can be overcome by doula assistance. The doula's presence provides emotional support during the preparation for childbirth, and the doula provides physical support by accompanying to overcome hunger, thirst, and pain. The aim of this study was to determine the effect of doulas assistance on the success of delivery.

Methods: This study is a descriptive observational study with a cross-sectional design conducted at a private hospital in Bali in the period January 2020 to January 2021. The inclusion criteria in this study were all pregnant women with gestational age 34 to 40 weeks who were willing to undergo the study. While the exclusion criteria in this study were pregnant women who experienced complications during childbirth and pregnant women with incomplete clinical and demographic data. All of the data was analyzed descriptively by using SPSS 25 and was presented by frequency.

Result: This study managed to collect as many as 100 pregnant women who will give birth with the help of a doula. It was found that as many as 60 people (60\%) gave birth vaginally. Then followed by 31 people (31\%) who underwent a Cesarean section with the help of a doula. There were also 5 people (5\%) and 4 people (4\%) who underwent epidural delivery and vacuum extraction with the help of a doula.

Conclusion: Doula assistance during labor can increase the confidence of the mother who will give birth and support the success of normal delivery.

Keywords: birth outcome, doula, normal childbirth.

Cite This Article: Sanjaya, I.N.H., Pemayun, C.I.M., Sakuntari, M, M.D.V., Purwanti, N.W.D., Gianni, N.P.N., Putri, N.L.M.D.M.C., Pirgantari, N.K.A., Satriani, N.L.M.D.L., Mintariani, F.S., Agustuni, A.A.W.P., Astuti, K.W . 2021. Doula Support in The Success of a Normal Delivery. Indonesian Society Of Perinatology 2(2): 29-31. D0I: 10.51559/inajperinatol.v2i2.13

\section{INTRODUCTION}

Today's maternity care practice in modern hospitals reduces the number of nurses who remain with mothers during and after delivery. This condition causes the mother to feel the loss of an individual who can support her during the birth process, especially patients their families do not accompany. ${ }^{1}$ One study found that new mothers expect their nurses to spend 53\% of their time providing support during labor. Still, only $6 \%-10 \%$ of the time, nurses are involved in labor support activities. ${ }^{2}$ To solve this problem, support people known as doulas are now present. Doulas are trained to provide physical, emotional, and informational support to women during labor, birth, and postpartum. Through the support provided by Doula, many pregnant women can reduce stress during preparation and postpartum. The positive effects of doula care are greater for socially disadvantaged, low-income, primiparous women who give birth in an unaccompanied hospital or experience language/cultural barriers. ${ }^{3}$

We report pregnant women giving birth using a doula at a private hospital in Bali. We counted 100 pregnant women who used doulas during labor. Of the 100 pregnant women who use doulas, $60 \mathrm{can}$ give birth normally per vagina without intervention, and 40 are delivered with interventions, such as vacuum extraction, epidurals, and cesarean section. Doulas help to reduce the odds of certain medical interventions during labor for low-risk women delivering at term. ${ }^{4-6}$ We aimed to examine the effect of support provided by doulas on a method of delivery, use of epidural anesthesia, and use of oxytocin during labor when compared with women receiving standard maternity care without a doula. The population we are interested in is low-risk women who intend to give birth vaginally

\section{METHOD}

This study is a descriptive observational study with a cross-sectional design conducted at a private hospital in Bali in the period January 2020 to January 2021. 
The inclusion criteria in this study were all pregnant women with gestational age 34 to 40 weeks who were willing to undergo the study. While the exclusion criteria in this study were pregnant women who experienced complications during childbirth and pregnant women with incomplete clinical and demographic data.

Doula assistance is carried out by experts who have been trained and certified as doulas. During the delivery process, the doula will be taught relaxation techniques, given massage and given information about the labor process and will be accompanied throughout the labor process starting until the baby is born. All data were collected and processed using the SPSS v.20. The data are described descriptively using tables to determine the number and proportion of each variable to the entire sample.

\section{RESULT}

This study managed to collect as many as 100 pregnant women who will give birth with the help of a doula. When viewed from age, the majority are under 30 years old, as many as 68 people $(68 \%)$, while the rest are the same or more than 30 years old. Then in terms of occupation, the majority of the sample in this study worked as housewives, as many as 58 people $(58 \%)$, followed by 28 people $(28 \%)$ as private workers, 11 people (11\%) as civil servants, and 3 people (3\%) as entrepreneur (Table 1).

Based on education level, the majority of the samples had senior high school education, as many as 48 people (48\%), followed by junior high school and university with 23 people (23\%), and only 6 people $(6 \%)$ with elementary school education. Then in terms of parity, the sample with parity 2 had a higher proportion in this study, namely 78 people $(78 \%)$, and the remaining 22 were women with parity $>2$, namely 22 people (22\%) (Table 1).

Then in terms of the delivery mechanism used, from 100 pregnant women who underwent delivery with the help of a doula, it was found that as many as 60 people $(60 \%)$ gave birth vaginally. Then followed by 31 people (31\%) who underwent a Cesarean section with the help of a doula. There were also 5 people

Table 1. Sample Characteristics of Women Giving Birth using Doula Support

\begin{tabular}{|c|c|c|}
\hline \multirow{2}{*}{ Variables } & \multicolumn{2}{|c|}{$N=100$} \\
\hline & $\mathbf{n}$ & $\%$ \\
\hline \multicolumn{3}{|l|}{ Age } \\
\hline$\geq 30$ years old & 32 & $32 \%$ \\
\hline$<30$ years old & 68 & $68 \%$ \\
\hline \multicolumn{3}{|l|}{ Job } \\
\hline Housewife & 58 & $58 \%$ \\
\hline Private Worker & 28 & $28 \%$ \\
\hline Civil Servant & 11 & $11 \%$ \\
\hline Entrepreneur & 3 & $3 \%$ \\
\hline \multicolumn{3}{|l|}{ Education Level } \\
\hline Elementary School & 6 & $6 \%$ \\
\hline Junior High School & 23 & $23 \%$ \\
\hline Senior Highschool & 48 & $48 \%$ \\
\hline University & 23 & $23 \%$ \\
\hline \multicolumn{3}{|l|}{ Parity } \\
\hline$\leq 2$ & 78 & $78 \%$ \\
\hline$>2$ & 22 & $22 \%$ \\
\hline \multicolumn{3}{|l|}{ Labor Mechanism } \\
\hline Normally per vagina & 60 & $60 \%$ \\
\hline Cesarean section & 31 & $31 \%$ \\
\hline Epidurals & 5 & $5 \%$ \\
\hline Vacuum extraction & 4 & $4 \%$ \\
\hline
\end{tabular}

(5\%) and 4 people (4\%) who underwent epidural delivery and vacuum extraction with the help of a doula (Table 1).

\section{DISCUSSION}

Childbirth is a physiological process and is an extraordinary event for a mother and her family. Management by skilled and reliable midwives and continuous support can result in a healthy and satisfying delivery. These conditions can also provide a pleasant experience for mothers. ${ }^{7}$ Childbirth is a difficult period for a mother, especially for primiparous mothers. Primiparous mothers will find it difficult because they do not have experience giving birth, so anxiety about the delivery process can arise. Therefore, family support and medical personnel are essential to mothers in the delivery process to help reduce anxiety. ${ }^{5}$ The process of childbirth has a severe psychological, social, and emotional impact on a mother and her family. Negative experiences received by a mother during childbirth will also negatively impact the mother, baby, and family. ${ }^{8}$ Mothers about to give birth often experience anxiety caused by maternal worries and fears about pregnancy, neuroendocrine changes during pregnancy, and predictions about birth outcomes. In general, anxiety during pregnancy is caused by maternal concerns regarding the difficulty of giving birth so that stress manifestations appear. ${ }^{9}$ A study in Turkey evaluated the association between fear of childbirth and maternal anxiety levels. It was found that $49.4 \%$ of nulliparous women and $50.6 \%$ of multiparous women were afraid of childbirth and had a significant relationship with prepartum anxiety. coupled with pain during labor will increase discomfort during the labor process. ${ }^{10}$

To reduce the anxiety and fear of mothers who are about to undergo labor, support from the early stages of labor is needed, for example, support from a doula. Doula support consists of several things. The doula's presence provides emotional support during the preparation for childbirth, and the doula provides physical support by accompanying to overcome hunger, thirst, and pain. In addition, the doula also provides information support related to the delivery process, problems 
that may arise, and how to overcome them. The doula will respect each patient's decision regarding the delivery route and help the mother have a good relationship with other medical personnel who will support the delivery. ${ }^{11-13}$ The study results showed that pregnant women who a doula assisted had a lower chance of complications than those who did not assist. In addition, the presence of a doula can also reduce complications and speed up the mother's start breastfeeding. There was a significant difference between the support received by mothers who were assisted by a doula and mothers who did not assist. This condition shows that mothers who are about to give birth need additional support from a doula, even though they already have the support of their closest family. ${ }^{14}$

The role of doulas in childbirth is that they are trained to provide physical, emotional, and information support to mothers who are preparing for the birth process and providing support until postpartum. The existence of support from the doula can reduce anxiety before giving birth, increase the confidence of the mother who will give birth, and help the mother control pain during labor., ${ }^{3,6}$ During the mother's contractions, the doula will help increase the mother's calmness from anxious and restless reactions. Biologically, the presence of a doula in this labor process will lead to the release of oxytocin so that the mother will feel calmer. ${ }^{15}$

The results of Thomas' 2017 research in New York City showed that doula support helps women make decisions regarding childbirth and plays an important role in managing labor pain. ${ }^{15}$ The results showed that the presence of a doula resulted in a $60 \%$ higher increase in normal delivery rates, reduced epidurals, and reduced the use of a vacuum to deliver the baby. These results indicate that pregnant women accompanied by a doula have better birth outcomes than mothers who give birth without the involvement of a doula. ${ }^{16}$ For mothers who underwent Caesarean section, the presence of a doula can help in emotional control, as well as assist in the process of caring for newborns. ${ }^{17}$

\section{CONCLUSION}

Doula assistance during labor can significantly increase the success of Normal delivery. In order to improve the normal delivery process, it is necessary to provide a midwifery care service strategy, namely providing doula assistance during the delivery process so that it can provide a feeling of security, comfort, and pleasure to the mother giving birth.

\section{ACKNOWLEDGMENTS}

We are thankful to the study team Clinic of Obstetric and Gynecologic Department Medical Faculty Udayana University Sanglah General Hospital, Outpatient Clinic Sanglah General Hospital Denpasar, Bali, Indonesia, and Kasih Medika Pregnancy School for their tireless efforts in article collection and reporting results.

\section{CONFLICT OF INTEREST}

All authors declared that there is no conflict of interest regarding this publication

\section{FUNDING}

This study was self-funded without any contribution from third party.

\section{AUTHOR CONTRIBUTION}

All authors contributed equally in the writing of this article

\section{ETHIC APPROVAL}

This study had been ethically approved by ethical commission of Faculty of Medicine Udayana University

\section{REFERENCES}

1. Papagni K, Buckner E. Doula Support and Attitudes of Intrapartum Nurses: A Qualitative Study from the Patient's Perspective. J Perinat Educ. 2006;15(1):11-8.

2. Tumblin A, Simkin P. Pregnant women's perceptions of their nurse's role during labor and delivery. Birth. 2001;28(1):52-6.

3. Vonderheid S., Kishi R, Norr KF, Klima C. Group prenatal care and doula care for pregnant women In Handler A., Kennelly J., \& Peacock N. (Eds.), Reducing racial/ethnic disparities in reproductive and perinatal outcomes. Evid from Popul Interv. :369-99.
4. Hodnett E, Gates S, Hofmeyr G, Sakala C, Weston J. Continuous support for women during childbirth. Cochrane Database Syst Rev. 2011;16(2):1-10.

5. Simkin P. Supportive care during labor: a guide for busy nurses. J Obs Gynecol Neonatal Nurs. 2002;31(6):721-32.

6. Fortier J, Godwin M. Doula support compared with standard care: Meta-analysis of the effects on the rate of medical interventions during labour for low-risk women delivering at term. Can Fam Physician. 2015;61(6):e284-92.

7. Hodnett DE, Gates S, Hofmeyr GJ, Sakala C, Weston J. Continuous support for women during childbirth. Cochrane Database Syst Rev. 2011;(2):1-110.

8. Stager L. Supporting women during labor and birth. Midwifery Today Int Midwife 2009. 2010;92:5-12.

9. Alderdice F, Lynn F. Factor structure of the Prenatal Distress Questionnaire. Midwifery. 2011;27(4):553-9. Available from: http:// dx.doi.org/10.1016/j.midw.2010.05.003

10. McCrea $\mathrm{H}$, Wright $\mathrm{ME}$, Stringer $\mathrm{M}$. Psychosocial factors influencing personal control in pain relief. Int $\mathrm{J}$ Nurs Stud. 2000;37(6):493-503. Available from: http:// dx.doi.org/10.1016/s0020-7489(00)00029-8

11. SIMKIN P, BOLDING A. Update on nonpharmacologic approaches to relieve labor pain and prevent suffering. J Midwifery Women $\square$ S Heal. 2004;49(6):489-504. Available from: http://dx.doi.org/10.1016/s15269523(04)00355-1

12. Sosa R, Kennell J, Klaus M, Robertson S, Urrutia J. The Effect of a Supportive Companion on Perinatal Problems, Length of Labor, and Mother-Infant Interaction. N Engl J Med. 1980;303(11):597-600. Available from: http:// dx.doi.org/10.1056/nejm198009113031101

13. Lundgren I. Swedish women's experiences of doula support during childbirth. Midwifery. 2010;26(2):173-80. Available from: http:// dx.doi.org/10.1016/j.midw.2008.05.002

14. Gruber KJ, Cupito SH, Dobson CF. Impact of Doulas on Healthy Birth Outcomes. J Perinat Educ. 2013;22(1):49-58.

15. Kennell J. Continuous Emotional Support During Labor in a US Hospital. JAMA. 1991;265(17):2197. Available from: http:// dx.doi.org/10.1001/jama.1991.03460170051032

16. Langer A, Campero L, Garcia C, Reynoso S. Effects of psychosocial support during labour and childbirth on breastfeeding, medical interventions, and mothers' wellbeing in a Mexican public hospital: a randomised clinical trial. BJOG An Int J Obstet Gynaecol. 1998;105(10):1056-63. Available from: http:// dx.doi.org/10.1111/j.1471-0528.1998.tb09936.x

17. McGrath SK, Kennell JH. A Randomized Controlled Trial of Continuous Labor Support for Middle-Class Couples: Effect on Cesarean Delivery Rates. Birth. 2008;35(2):92-7. Available from: http://dx.doi.org/10.1111/ j.1523-536x.2008.00221.x

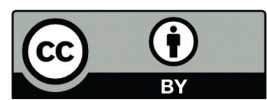

This work is licensed under a Creative Commons Attribution 